\title{
THE NEW PROCEDURE FOR IDENTIFICATION OF INFRASTRUCTURE ELEMENTS SIGNIFICANCE IN SUB-SECTOR RAILWAY TRANSPORT
}

The paper focuses on the problem of importance/significance elements evaluation in the railway transport infrastructure sub-systems. It contains main features of the proposed theoretical approach to the significance assessment of the key typological elements of railways infrastructure. The research also attempted to design an effective methodology, which allows assessing the significance of infrastructure objects. The purpose of the multi-criteria assessment of selected sections and typological objects is to select the most significant/important ones from the point of view of maintaining the railway operability. The selection is conducted using the assessment of a section or an object, following the pre-defined criteria. The developed methodology should help to set a group of potential elements of critical infrastructure in the railway sub-sector.

Keywords: transportation, railway infrastructure objects, risk assessment, criterion, multi-criterial decision, critical elements

\section{Introduction}

The problem of Critical Infrastructure (CI) and its security, especially the resilience assessment of the most important elements and services of infrastructure systems and their efficient protection is a topical problem nowadays. Despite the numerous publications [1], [2], [3] and proposed approaches [4], [5], one cannot apply any universally accepted approach to understand the relations between individual infrastructures. The crucial problem here is how to identify the potential CI elements, based on their parameters and properties or mutual relations. Several influential papers [1], [2], [3], [6], [7] focus on identification methodology of critical sections and elements of the transport infrastructure. The Slovak methodology of the national and the European CI elements determination [8] is regulated by the Act 45/2011 Coll. on Critical Infrastructure [9]. The Government of the Slovak Republic (hereinafter SR), based on the proposal of the Slovak Ministry of Interior, according to $\S 4$ letter c) of the Act No. 45 /2011 Collection of Laws on critical infrastructure, determined the so-called sector criteria, European sector criteria, crosssectional criteria and European cross-sectional criteria that are at present classified. Due to this reason, the proposal of procedures for objective determination of the set of the so-called "potential CI elements" is an important objective not only of field experts, but in academic environment, as well. The paper focuses on the problem of identification of important infrastructure elements in the transportation sector - railway sub-sector. It contains characteristics and main features of the proposed theoretical approach to identification of importance of defined typological elements of the transport infrastructure. By applying the original developed procedure, it is possible to decide objectively about the structure of the subset of potential CI elements in the railway subsector. At present, a respective software support for its practical application is being developed.

\section{The current state of the railway infrastructure elements significance valuation}

The main objectives of all participating countries of the EPCIP (European Program for Critical Infrastructure Protection) [10], in the transportation sector are to identify the most important elements of transport infrastructure, to reveal and assess their risks that can possibly negatively affect the transportation system functioning and also to prepare efficient protection measures. However, the EPCIP countries often apply different procedures for selection of significant infrastructure elements and their risk and resilience assessment. Nowadays,

\footnotetext{
* ${ }^{1}$ Bohus Leitner, ${ }^{2}$ David Rehak, ${ }^{3}$ Robertas Kersys

${ }^{1}$ Faculty of Security Engineering, University of Zilina, Slovakia

${ }^{2}$ Faculty of Safety Engineering, VSB - Technical University of Ostrava, Czech Republic

${ }^{3}$ Faculty of Mechanical Engineering and Design, Kaunas University of Technology, Lithuania

E-mail: Bohus.Leitner@fbi.uniza.sk
} 
Table 1 An example of the hazardous events

\begin{tabular}{|c|c|c|c|c|c|c|}
\hline $\begin{array}{l}\text { Methodical / } \\
\text { procedure }\end{array}$ & $\begin{array}{c}\text { Slovakia - Risk } \\
\text { analysis in sector } \\
\text { Transport }\end{array}$ & $\begin{array}{l}\text { Czech rep. - } \\
\text { CritInfo }\end{array}$ & $\begin{array}{l}\text { Germany } \\
\text {-SECMAN }\end{array}$ & USA -RAMCAP & $\begin{array}{l}\text { Denmark - } \\
\text { RVA }\end{array}$ & $\begin{array}{c}\text { Germany - } \\
\text { SeRoN }\end{array}$ \\
\hline $\begin{array}{c}\text { Sector / sub-sector } \\
\text { of Critical } \\
\text { infrastructure }\end{array}$ & $\begin{array}{l}\text { Road and } \\
\text { railway transport } \\
\text { subsector }\end{array}$ & $\begin{array}{l}\text { Transport - all } \\
\text { subsectors }\end{array}$ & $\begin{array}{c}\text { Road } \\
\text { transport }\end{array}$ & $\begin{array}{c}\text { Transport - all sub- } \\
\text { sectors }\end{array}$ & $\begin{array}{l}\text { Transport - all sub- } \\
\text { sectors }\end{array}$ & $\begin{array}{c}\text { Road } \\
\text { transport }\end{array}$ \\
\hline $\begin{array}{l}\text { Approach to } \\
\text { determine }\end{array}$ & $\begin{array}{l}\text { Sections, } \\
\text { objects }\end{array}$ & $\begin{array}{l}\text { Sections, } \\
\text { objects }\end{array}$ & $\begin{array}{l}\text { Sections, } \\
\text { objects }\end{array}$ & $\begin{array}{l}\text { Particular } \\
\text { element }\end{array}$ & Particular element & $\begin{array}{l}\text { Sections, } \\
\text { objects }\end{array}$ \\
\hline $\begin{array}{l}\text { Determination of } \\
\text { criteria }\end{array}$ & Yes & Yes & Partially & No & No & Partially \\
\hline $\begin{array}{l}\text { Evaluation of } \\
\text { criteria }\end{array}$ & Threshold limits & Point scale & Qualitative & Not defined & Not defined & Qualitative \\
\hline Risk assessment & Yes & Yes & Partially & Yes & Yes & Yes \\
\hline
\end{tabular}

it is possible to use a wide variety of different methods for risk assessment or comprehensive parametric assessment of infrastructure element resilience. The CI experts are continuously creating or modifying approaches that enable them to conduct more specific assessment of system parameters of selected groups of elements, the so-called typological objects. They have been frequently involved in designing procedures for selecting potential CI elements, identifying the active factors, assessing the risk level and proposing measures for protection of the most significant/ important CI systems and services [11].

The European cross-sectional criteria are identical in all the participating countries, but they are not defined clearly, e.g. by determining the limit values of observed parameters. The crosssectional criteria mostly focus on failure impact of a significant infrastructure element only. On the contrary, the sector criteria in the railway sub-sector (but also in other transport sub-sectors) do not primarily focus on the assessment of an element failure impact, but they represent specific technical parameters for infrastructure element assessment. The sector criteria, except for the Czech Republic, are classified in all the EU countries and that is why it is only possible to assume and not clearly state which criteria were applied for identification and selection of the set of CI elements [4], [5], [7], [12], [13].

The approaches and methodology for identification of the CI set elements generally depend on the country as each country uses a specific methodology. Table 1 shows a basic comparison of approaches used in various countries.

\section{Procedure for identification of potential CI elements in the railway sub-sector}

Suitable model methodologies mainly include the German methodology SECMAN [13], the Czech methodology CritInfo [5], but also other mostly road transport-related methodologies. The criteria generally focus on assessment of transport infrastructure performance and at the same time on its possible failure impact.

The general methodology SECMAN mostly deals with road infrastructure with the aim to define the precise criteria for assessment of structural properties of the most important infrastructure elements (tunnels and bridges). For the mentioned types of objects, qualitative criteria were defined as a basis for creation of typological objects of bridges and tunnels. A specific vulnerability value was calculated for each typological object. Based on the above mentioned approaches, a universal procedure for defining the set of potential CI elements in the railway subsector was designed and verified.

The proposed procedure consists of subsequent steps:

1. defining and assessment of basic characteristics of line elements - sections - in the area of infrastructure,

2. identification of important sections and determination of the "Index of Section Importance $I_{U}$ " - it means selection of the most important sections,

3. defining and assessment of basic typological objects in a section (tunnels, bridges, stations, centralized traffic control and other important technological elements of railway infrastructure,

4. identification of important elements and determination of the "Index of Object Importance $I_{o}$ ", based on the calculated values of "General Index of Object Importance $I_{V}$ " and "Specific Object Index I $\mathbf{I}_{\mathrm{S}}$ " - it means selection of the most important objects,

5. quantification and interpretation of "Overall Index of Criticality $I_{K}$ ".

The procedure is based on the assessment according to [14], [15] and applies multi-criteria assessment. The purpose of the multi-criteria assessment of selected sections and objects is to select the most significant ones from the point of view of maintaining the railway operability [16]. The selection is conducted using the assessment of a section or an object following 


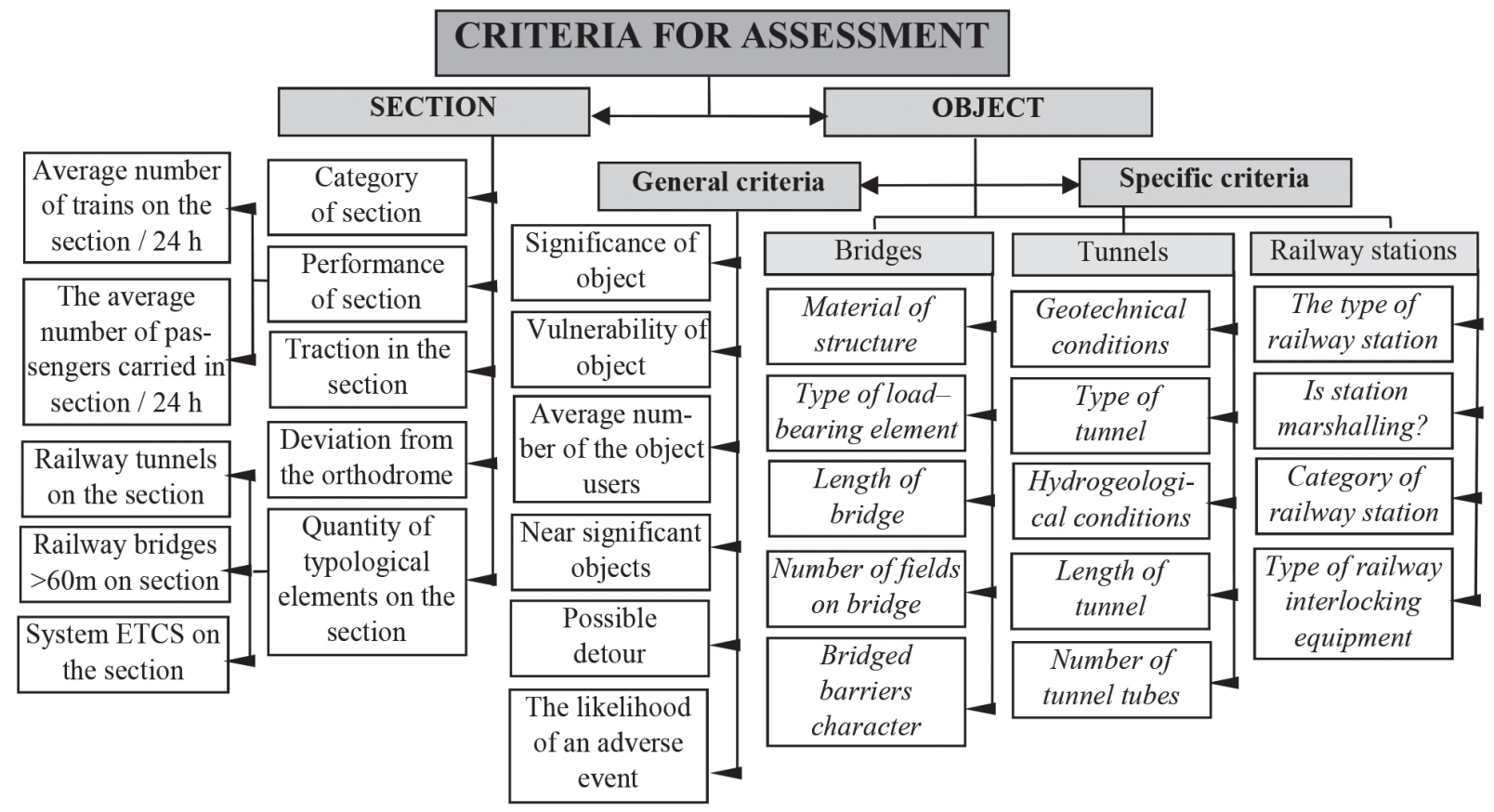

Figure1 Structure of assessment criteria used in the proposed procedure

pre-defined criteria. For importance assessment of sections and objects, different criteria are defined. On the level - objects - the assessment criteria according to their significance can be divided into general and specific criteria. The structure of proposed criteria is demonstrated by Figure 1.

The basic structure of the proposed procedure of the potential CI element identification and assessment in the field of railway infrastructure is shown in Figure 2.

The above mentioned activities help to identify the important sections of the railway infrastructure on the network level and on the object level. The output of the assessment process is a set of important sections and objects located on them - as the potential $\mathrm{CI}$ elements in the railway sub-sector.

For more objective assessment of sections applying individual criteria, it is necessary to determine weight coefficients of particular criteria. This is conducted based on their (pair-wise) comparison following the Saaty method [17], [18] of analytic hierarchies. Based on weight coefficients of criteria $w$ and the attributes of the assessed sections / objects expressed by the point value, it is then possible to acquire the Index of section importance $I_{U}$ and Index of object importance $I_{o}$. Their calculation is based on the relation formed by the sum of products of the point value for section / object and the weights of their individual criteria $w_{i}$. Before identifying the most important elements of the railway infrastructure, it is necessary to conduct several preparatory activities:

- to define the selected area of interest,

- to divide the railway track in the area of interest into discrete sections,

- $\quad$ to select parameters and criteria of assessment [15].

\section{PHASE 1: Assessment on the section level - line infrastructure elements}

The aim of the first phase of the assessment procedure is to identify the most important sections of railway track in the area of interest and to determine the Index of Section Importance $I_{U}$.

In the proposed procedure, the selected sections are assessed according to five criteria ( $\mathrm{K} 1-\mathrm{K} 5)$ that are assigned points following the scale designed by authors. The pairwise comparison makes possible to state the order of importance of the assessment criteria for sections. The following order of importance of the section criteria is used: $\mathbf{K} \mathbf{1}=$ section performance, $\mathbf{K} \mathbf{2}=$ section category, K4 = occurrence of important typological elements, K5 $=$ deviation from the orthodrome and the least important criterion K3 = traction on section.

Naturally, the individual assessment criteria could become a subject of discussion. For example, the section performance does not have to be the most important criterion. From the point of view of maintaining primary functions of the state, it is important what is being transported in a given section. The load of $50000 \mathrm{t}$ of cars would not be of the same importance for the state as $50000 \mathrm{t}$ of coal for a power plant. The outcome of the first phase is the list of all sections of the railway infrastructure in the area of interest and the corresponding value of the Index of section importance $I_{U}$ which can be expressed as follows

$I_{U}=\sum_{i=1}^{5} \frac{\left(K_{i} \times w_{i}\right)}{5}$

where $K_{i}$ is point value of the $i$-th criterion for a given section, $w_{i}$ is weight coefficient of the $i$-th criterion. The theoretical - benchmark 


\section{kOMNIKOCle}

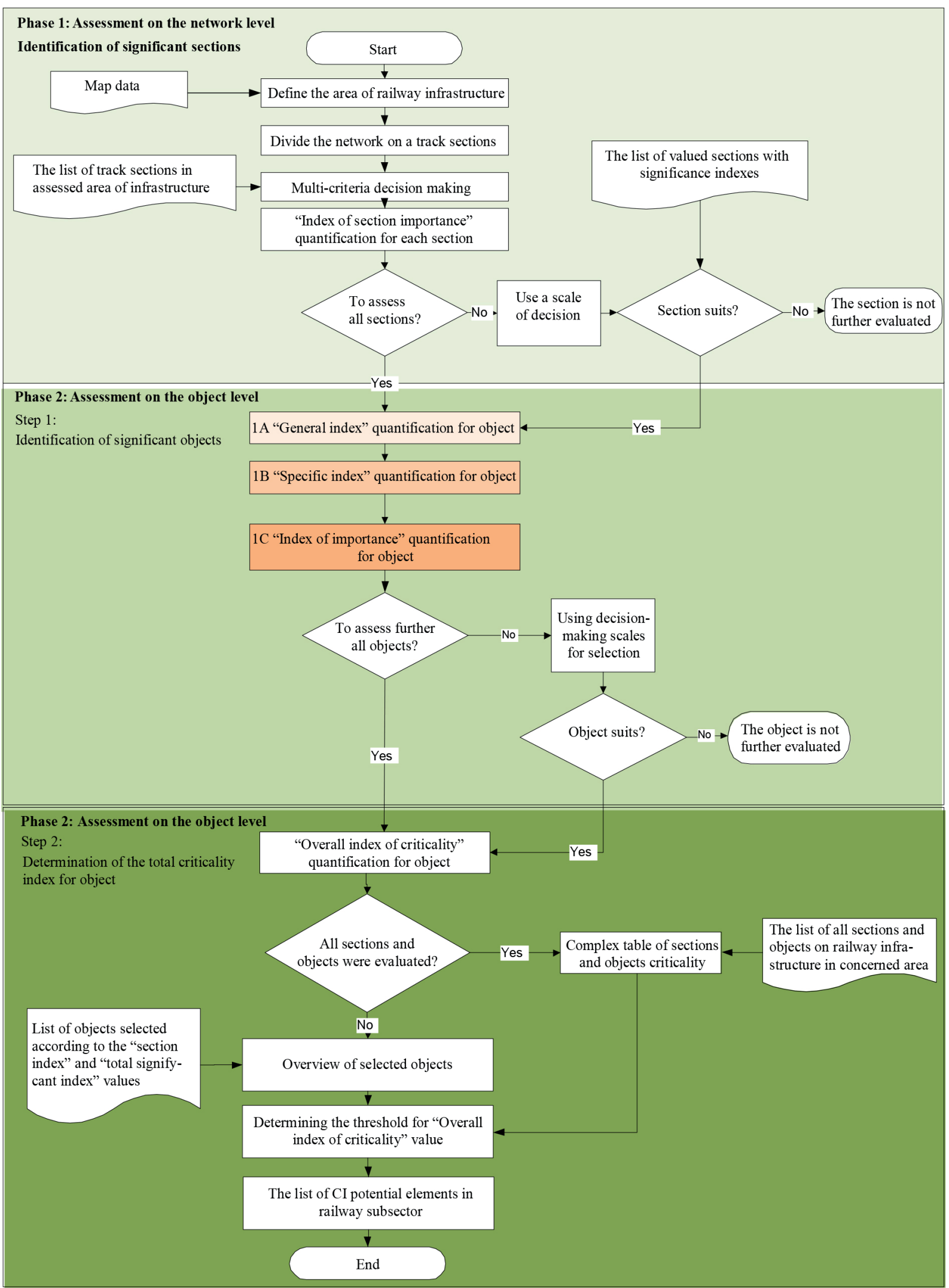

Figure 2 Procedure for CI elements identification in railway sub-sector 


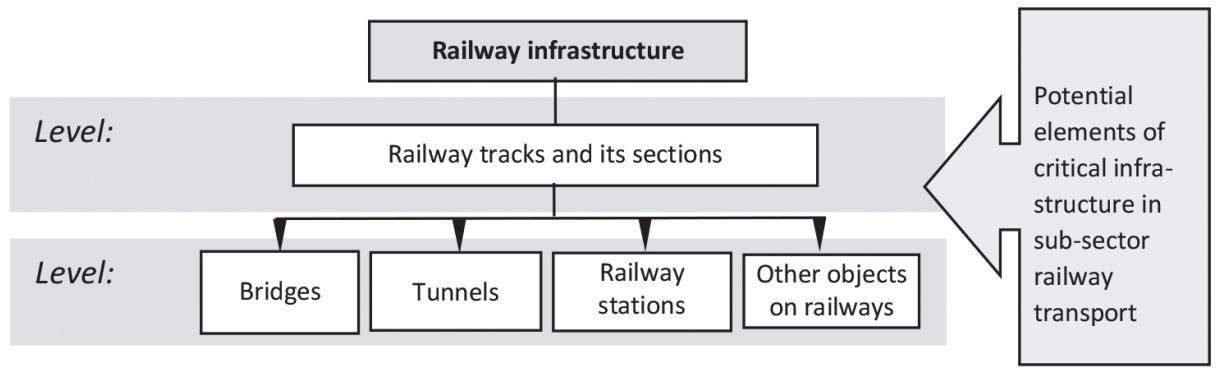

Figure 3 Typological objects

- section (maximum possible value) reached the value $I_{U}=12.6$ and the following relation is valid

$$
\begin{aligned}
I_{U} & =\frac{K_{1} \times w_{1}+K_{2} \times w_{2}+K_{3} \times w_{3}+K_{4} \times w_{4}+K_{5} \times w_{6}}{5}= \\
& =\frac{5 \times 5+5 \times 4+2 \times 1+2 \times 3+5 \times 2}{5}=\frac{63}{5}=12.6
\end{aligned}
$$

\section{PHASE 2: Assessment on the object level - point infrastructure} elements

The aim of the second phase is to identify the most important objects in the sections, selected in the first phase - i.e. in the most important railway sections in the area of interest, as well as to determine the Index of object criticality $I_{o}$. The most important elements of railway infrastructure will be understood as typological objects. It is possible to assume that the primary typological objects - railway bridges, railway tunnels, railway stations, dispatching centers for remote-controlled tracks etc. - will probably form a set of potential CI elements in the railway subsector. The phase of assessment on the object level consists of two steps:

\section{PHASE 2 - Step 1: Determination of the Index of object importance $I$.}

An expected outcome is a list of all objects in the most important sections (selected in the 1st phase). Each object is assigned a respective value of Index of object importance $I_{O}$ and for its quantitative expression it is necessary to determine:

A. General index of object importance $I_{r}$ : detailed section analysis in order to create a list of section objects and define their operational and security attributes. The objects are assigned points according to defined scales for individual criteria (VK1 - VK6). The order was determined by pair wise comparison of criteria. The most important criterion is VK6 - probability of occurrence of an undesirable event. The other criteria, respectively, are: VK3 - number of object users, VK4 - object environment, VK2 - object vulnerability, VK5 - possible detour and VK1 - object importance.

For the sake of further clarification, e.g. in criterion VK5, it is possible to consider replacing railway transport by road transport (which is besides detour the most frequent method how to provide transport in case of distortion or destruction, etc. of an important element of transport infrastructure. Based on the assigned points VK and the weight coefficient of the criterion $w$, for the General index of object importance the following relation is valid:

$$
I_{V}=\sum_{i=1}^{5} \frac{\left(V K_{i} \times w_{i}\right)}{5}
$$

where $V K_{i}$ is value of the $i$-th criterion for the given object, $w_{i}$ is weight coefficient of the $i$-th criterion.

B. Specific index of object importance $\mathbf{I}_{\mathbf{s}}$ : detailed analysis of an object for the purpose of defining its typology and attributes. Based on assessment of specific parameters of typological objects - bridges, tunnels, stations, terminals or other objects, it is possible to determine the value of the Index $\mathrm{I}_{\mathrm{s}}$, following the predefined matrices of individual groups of typological groups (Figure 3).

For each typological group, the Specific Index of Object Importance $\mathrm{I}_{\mathrm{s}}$ is determined as:

$I_{S}=\sum_{i=1}^{5} \frac{\left(S K_{i} \times w_{i}\right)}{5}$

where $S K_{i}$ is value of the $i$-th specific criterion for the given object, and $n$ is number of relevant specific criteria selected for the object. Based on the set of specific criteria $\mathrm{SK}_{\mathrm{i}}$ [14], their combinations and object types, 12 types of bridge structures, 6 types of tunnels and 8 types of railway stations were defined. Each object was clearly assigned a specific value of the index $I_{S}$, specifying its vulnerability (or resilience) level. The determined value was based on specific object properties and parameters.

C. Summary value of the object importance: it's called Index of object importance $I_{o}$. Here, the following relation is valid:

$I_{O}=\frac{I_{V}+I_{S}}{2}$

where $I_{v}$ is the value of the General index of object importance, $I$ is the value of the Specific index of object importance. The Index of object importance $I_{O}$ must be determined separately for each typological group, because the specific criteria of each typological group are different, featuring different point values and different maximum value each typological object can reach. The maximum possible (reference) values of the Index of object importance $I_{O}$ for each typological group are stated in Table 2 . 
Table 2 Maximum values of the Object importance index

\begin{tabular}{cccc}
\hline $\begin{array}{c}\text { Typological } \\
\text { group }\end{array}$ & $\begin{array}{c}\text { Maximal value of General index of } \\
\text { object importance Iv }\end{array}$ & $\begin{array}{c}\text { Maximal value of Specific index } \\
\text { of object importance } \mathrm{I}_{\mathrm{s}}\end{array}$ & $\begin{array}{c}\text { Maximal value of Total index of } \\
\text { object importance } \mathrm{I}_{\mathrm{O}}\end{array}$ \\
\hline Bridges & $\mathrm{I}_{\mathrm{V} \max }=15$ & 8.4 & 11.7 \\
Tunnels & & 7.4 & 11.2 \\
Railway stations & & 7.5 & 11.25 \\
\hline
\end{tabular}

Table 3 Scale for assessing - Overall criticality index of object

\begin{tabular}{ccc}
\hline Level & Scale for assessing & Index I $_{\mathrm{K}}$ \\
\hline 1 & Very important / Very critical & $0.90-1.00$ \\
2 & Important / Critical & $0.75-0.90$ \\
3 & Moderately important / Moderately critical & $0.65-0.75$ \\
4 & Low important / Low critical & $0.50-0.65$ \\
5 & Insignificant / not critical & $0.00-0.50$ \\
\hline
\end{tabular}

PHASE 2 - Step 2: Calculation of the Overall Criticality Index $I_{K}$

The Overall Criticality Index $I_{K}$ is determined based on the above mentioned data and is determined by the following relation:

$$
I_{K}=\frac{I_{U_{i}}+I_{O_{i}}}{\max \left(I_{U_{i}}+I_{O_{i}}\right)}
$$

where $I_{U i}$ is a resulting value of Index of Importance for section $i, I_{O i}$ is a resulting value of the Index of Importance for object $i, \max \left(I_{U_{i}}+I_{O_{i}}\right)$ is the maximum possible value of the sum of values of indices $\mathrm{I}_{\mathrm{U}}$ and $\mathrm{I}_{\mathrm{O}}$ for a particular object $i$. The Overall Criticality Index $I_{K}$ always acquires values from the interval $<0$; 1>. The principle of identification or determination of the object importance lies in comparing the acquired number of points of the assessed object with the maximum number of points a given typological object is able to reach. To determine the level of criticality, a scale with value range of IK was defined according to Table 3.

In a conducted case study, the authors decided that the objects reaching values over 0.75 can be considered as objects that compose a set of potential CI elements. Why the value 0.75 ? Interestingly, the users can define the limit values according to their needs and according to the desired size of the set of important elements.

It is obvious that if the set of important elements of transport infrastructure is too large, the costs for securing prevention or subsequent protection measures will be higher. If the criterion limit for including the object to the list is set arbitrarily, (e.g. value 0.5 or 0.95 ), and the group of potential CI elements includes arbitrarily high number of transport infrastructure elements, the final range of carried out measures will always depend on financing possibilities of their protection. For example, in compliance with $\S$ 9, para. 4 of the Act [9], the operator of a CI element is entitled to a financial support (from the respective Ministry) to meet the duties related to performing security measures for a CI element protection. It is thus possible to select hundreds of elements and label them as "vitally important". If financial support for security measures is not available, the fact whether the object is on the CI element list or not will not protect it against any potential threat. It also means that the value 0.75 - benchmark selected by methodology authors, cannot be understood dogmatically. A set of railway infrastructure objects acquired in the stated way needs to be further assessed applying objective risk assessment methods [19]. Based on results of the risk assessment and the resilience level assessment of the CI systems and services, it is possible to decide objectively about the size and structure of CI system in a specific sector/sub-sector on national and European level.

\section{Conclusions}

The procedure was designed in the way to provide an assessment of railway infrastructure on the network and object levels. The aim of this methodology is to identify important railway sections and determine values of section importance. Subsequently, it is necessary to define and assess typological objects in the section and set the values of object importance. This enables us to focus attention on prevention checks, maintenance and organizational measures for securing the desired protection level. The authors are aware of the fact that the designed procedure is only one of possible steps applicable in a comprehensive process of the CI element selection, specifically in railway infrastructure (bridges, tunnels and railway stations). It is necessary to realize here that the proposed procedure does not include all the important attributes of conducted transport services, e.g. characteristics or commodity mix transported in individual track sections, redirecting the flow of goods or people to another track section. 
In the moment of redirecting the flow, the importance of element value changes (the criterion values for selected elements of railway infrastructure change) and the original element that seemed to be critical loses its importance. There are also problems of possible impact of replacement of the railway transport by the road transport and assessment of railway infrastructure elements in terms of their uniqueness. For example, the only 100-m-long bridge on a 100-km-long section will be of different importance than a 100 -m-long bridge on a $20-\mathrm{km}$-long section with 5 other bridges, even if the tracks were loaded identically.

The most significant deficiency of the CI element determination and protection is the fact that no EU document states exhaustively the required level of the $\mathrm{CI}$ element protection in the transport sector, either on the European or national level. The need is even more obvious if we realize that it was the EU that started discussion on this problem. From this point of view, it is not clear what final state of element protection should be reached. There is space for more extensive research (e.g. scientific project, study, final thesis, etc.). For example, it should be possible to quantify that a railway station with more than 30000 passengers per day must have a CCTV and a security guard service and a different station with more than 15000 passengers per day at least a CCTV, etc. A similar system can be adopted as a protection measure for other typological elements, e.g. bridges, tunnels, etc. Our research has revealed other areas that need to be focused on in terms of functionality and versatility:
- adding more typological objects to typological groups and determination of their specific parameters and criteria (e.g. energy supplying systems, controlling systems, etc.),

- detailed definition of main criteria and vulnerability analysis for each object type in each typological group,

- completing the next process step: comparison of objects based on another index that would consider some risk factors of objects,

- creation of software tool enabling automated assessment of object criticality that would be based on developed procedure and current railway infrastructure databases,

- cooperation with GIS systems in presentation of object location in the area of interest and criticality parameters of the analyzed sections / objects on a map.

Systematic solution of the above mentioned areas of problems and partial activities in the processes of identification and importance assessment and object resilience in infrastructure networks can contribute to more efficient processes of security management and protection of important sections and elements of transport infrastructure.

\section{Acknowledgements}

This work was supported by project $1 / 0240 / 15$ "Process model of critical infrastructure safety and protection in the transport sector" and by the project VI20152019049, "Dynamic Resilience Evaluation of Interrelated Critical Infrastructure Subsystems".

\section{References}

[1] BAKER, J.: A Vulnerability Assessment Methodology for Critical Infrastructure Facilities [online]. James Madison University, 2005. Available: pphttp://www.jmu.edu/iiia/wm_library/Vulnerability_Facility_Assessment_05-07.pdf.

[2] KAUNDINYA, I., MAYER, M., KRIEGER, J., ROTHENPIELER, S.: Security of Road Transport Networks - Identifying and Assessing Critical Road Infrastructure [online]. Transport research area, Paris, 2014. Available: http://tra2014.traconference.eu/ papers/pdfs/TRA 2014_Fpaper_17827.pdf.

[3] LOVECEK, T., REHAK, D., SISER, A., HROMADA, M.: Resistance of Passive Security Elements as a Quantitative Parameter Influencing the Overall Resistance and Resilience of a Critical Infrastructure Element. The tenth International Conference on Emerging Security Information, Systems and Technologies (SECURWARE 2016), France, 200-205, 2016.

[4] ONDREJKA, R.: Risk Analysis of Transport Sector - Subsectors Road Transport and Rail Transport (in Slovak). Final report. Research Institute of Transport, Zilina, p. 844, 2014.

[5] FUCHS, P., SOUSEK, R., ZAJICEK, J., HAVLICEK, J.: Transport Infrastructure as Element of the State Critical Infrastructure: Assessment of Criticality in Czech Republic (in Czech). VSBM Kosice, p. 85, 2011.

[6] SVENTEKOVA, E., LUSKOVA, M., DVORAK, Z.: Use of Network Analysis in Conditions of Critical Infrastructure Risk Management. The 20th World Multi-Conference on Systemics, Cybernetics and Informatics (WMSCI 2016), USA, II., 247-250, 2016.

[7] NOVOTNY, P., MARKUCI, J., TITKO, M., SLIVKOVA,S., REHAK, D.: Practical Application of a Model for Assessing the Criticality of Railway Infrastructure Elements. Proceedings of scientific works, VSB - Technical university Ostrava, 26-32, 2015.

[8] Council of the EU, 2008. Non-Binding Guidelines for the Application of the Directive on the Identification and Designation of European Critical Infrastructures and the Assessment of the Need to Improve Their Protection [online]. Available: http://register.consilium.europa.eu/doc/srv?1=EN\&f=ST\%2015616\%202008\%20INIT [accessed: 2017-05-18]. 


\section{KOMNIKCCle}

[9] Act 45/2011 Collection of Laws on Critical Infrastructure (in Slovak) [online]. Bratislava, 2011. Available: http://www. zakonypreludi.sk/zz/2011-45.

[10] European Programme for Critical Infrastructure Protection [online]. Available: http://eur-lex.europa.eu/legal-content/SK/ TXT/?uri=URISERV\%3Al 33260.

[11] Council Directive 2008/114/EC on the Identification and Designation of European Critical Infrastructures and the Assessment of the Need to Improve Their Protection [online]. Available: http://eur-lex.europa.eu/legal-content/EN/TXT /?uri=CELEX\%3A32008L0114.

[12] RAMCAP Framework. ASME Innovative Technologies Institute [online]. 2006. Available: http://www.personal.psu.edu/jsd222/ SRA311/RAMCAPframework_Risk_Analysis_and_Manage.pdf.

[13] SECMAN Project [online]. Available: http://www.secman-project.eu/.

[14] JANUSOVA, L.: Increasing the Objectivity of Identification Critical Infrastructure Elements in Transportation Sector (in Slovak). Dissertation work, University of Zilina, p. 149, 2015.

[15] JANUSOVA, L., LEITNER, B.: Procedure to Identification of Critical Infrastructure Potential Elements in Railway Sub-Sector (in Slovak). Crisis Management, 2, 5-13, 2015.

[16] BREZNiCKA, A., CHOVANEC, A., STODOlA, J.: Discrete Simulation with a Variable Time Step in Assessing Costs to Mission. International Conference on Military Technologies (ICMT 2015), Czech Republic, 103-106, 2015.

[17] DVORAK, Z., LUSKOVA, M., HRUZA, P., SOUSEK, R.: Complex Automated Information System for Remote Management of Crisis Situations in Rail Transport. Communications: Scientific Letters of the University of Zilina, 15(3), 83-88, 2013.

[18] SAATY, T. L: Analytic Hierarchy Process. McGraw-Hill, New York, USA, 1980.

[19] SAATY, T. L.: Decision-Making with the AHP: Why is the Principal Eigenvector Necessary. European Journal of Operational Research, 145(1), 85-91, 2003. 